\title{
Archéopages
}

Archéopages

Archéologie et société

$45 \mid 2017$

De la terre au pot

\section{Expérimentation sur l'utilisation des argiles sableuses}

Sonja Willems, José Fernandes, Catherine de Casas et Patrick Quennehen

\section{(2) OpenEdition}

1 Journals

Édition électronique

URL : https://journals.openedition.org/archeopages/3201

DOI : 10.4000/archeopages.3201

ISSN : 2269-9872

Éditeur

INRAP - Institut national de recherches archéologiques préventives

Édition imprimée

Date de publication : 1 mars 2018

Pagination : 80-81

ISSN : 1622-8545

\section{Référence électronique}

Sonja Willems, José Fernandes, Catherine de Casas et Patrick Quennehen, «Expérimentation sur

l'utilisation des argiles sableuses ", Archéopages [En ligne], 45 | 2017, mis en ligne le 01 janvier 2020, consulté le 04 juin 2021. URL : http://journals.openedition.org/archeopages/3201 ; DOI : https:// doi.org/10.4000/archeopages.3201 


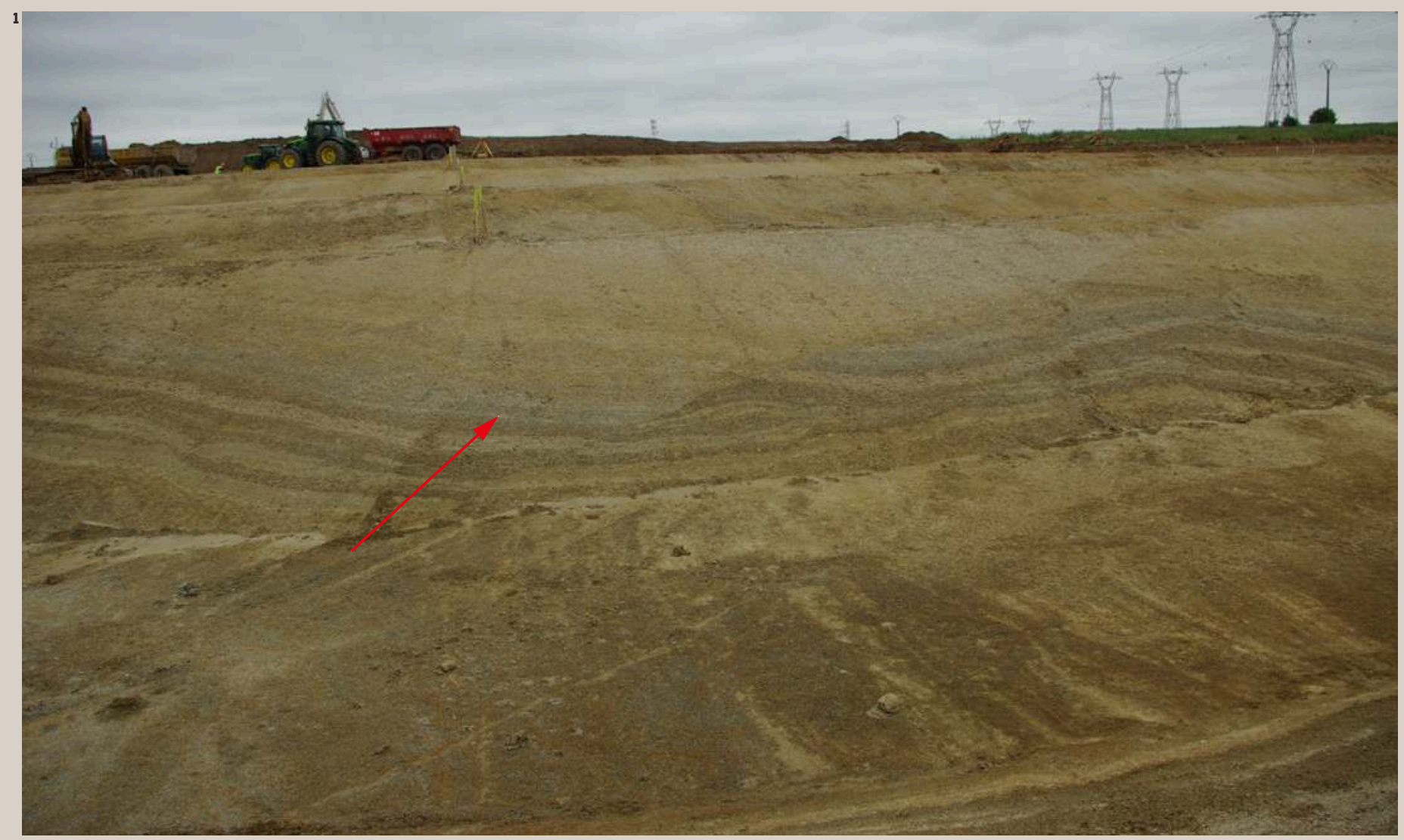

\section{Expérimentation sur l'utilisation des argiles sableuses}

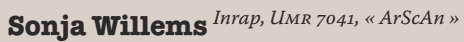

José Fernandes Poterie de Luc

Catherine de Casas ${ }^{\text {Poterie de Luc }}$

Patrick Quennehen Parc archéologique de Samara



La butte tertiaire du Mont Houy à Famars, coiffée des sables du Quesnoy (Vallin, Prévost-Boure, 1990) renferme, à quelques mètres sous la surface actuelle, différentes couches d'argiles [ill. 1]. Bien visible dans le paysage, elle se situe à quelques centaines de mètres de la fouille du Technopôle-Transalley (Clotuche, 2013 ; Clotuche, à paraître). Au cours de celle-ci, douze fours de potiers ont été mis au jour (Willems, Borgers, 2016), complétant le corpus constitué depuis les années 1970 dans l'agglomération (Beaussart, 1976 ; Truffeau-Libre, Vanbrugghe, 1994 ; Herbin et al., 2005). La proximité d'une zone de production céramique et d'une source d'argile a amené à un questionnement sur les propriétés des matières premières et leur adaptation à l'activité potière. Avant d'analyser scientifiquement celles-ci, une expérimentation a été menée par le tournage de copies de vases antiques avec l'argile prélevée afin de déterminer les gestes nécessaires à l'utilisation de cette dernière et reconnaître les similitudes avec les produits retrouvés dans le quartier du Technopôle.

Les résultats de ces expérimentations ont permis de mieux comprendre la production antique, et la raison de certains rejets. Les marnes de la Rhonelle, petite rivière bordant l'agglomération, n'ont pas servi à l'expérience, car elles ont été considérées comme trop organiques 
1. Différentes couches argileuses ont été mises en évidence lors de l'aménagement d'un bassin au pied du Mont Houy.

2.Vases provenant de

l'expérimentation mené sur l'argile du Mont Houy par P. Quennehen (pot tonnelet,jatte carénée et pot tronconique enfumé). La surface orangée est légèrement sableuse

et très fine.

3. a. Cassure fraîche d'un rebut de cuisson issu du four 1335 , avec présence d'argilites.

b.Aperçu d'argilites criblant la surface.

4. Les argilites sont parfois telles que, lors du séchage et de la cuisson, la paroi éclate ou se fissure autour des inclusions.
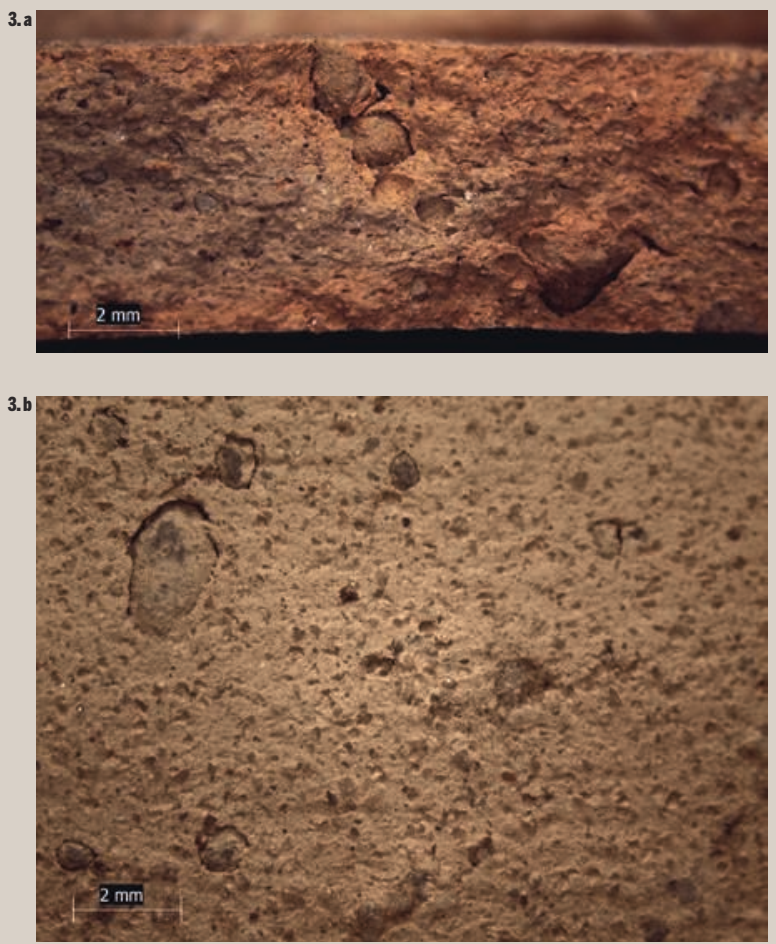

pour se prêter à un tournage. Fllles ont seulement fait l'objet d'un mélange à l'argile sableuse du Mont Houy pour tester une proximité chimique avec les productions à pâte calcaire.

L'expérimentation sur l'argile tertiaire a été menée en 2012 et 2013 , dans le cadre du $51^{\mathrm{e}}$ congrès de la Société française d'étude de la céramique antique en Gaule (SFFCAG) à Amiens et du projet «De la terre à la céramique " du parc archéologique de Samara (La Chaussée-Tirancourt, Somme). Un échantillon a été confié à Patrick Quennehen, potier de Samara, et un second à José et Catherine Fernandes-de Casas, céramistes à la Poterie de Luc (La Salvetat-Peyralès, Aveyron). Les deux essais ont livré des résultats divergents. P. Quennehen a tourné facilement l'argile, qui s'est révélée suffisamment élastique et plastique, prête à l'emploi sans traitement préalable (décantation, broyage ou séchage). Des pots tonnelets, des jattes carénées et un vase tronconique, cuits en mode oxydant, présentent une surface très propre et fine, légèrement granuleuse [ill. 2]. Un résultat complètement opposé a été obtenu par les potiers J. Fernandes et C. de Casas. Ils ont laissé reposer l'argile dans l'eau pendant 48 heures avant utilisation. Puis des plaques ont été produites pour en évaluer l'élasticité, la plasticité et le séchage. Des boulettes d'argile non oxydée subsistaient dans la pâte, non dissoutes par le trempage. Le tournage, très difficile, a été abandonné. Plusieurs méthodes pourraient être envisagées pour éliminer ces particules : séchage puis broyage, battage ou décantation dans de grands bacs d'eau, permettant à l'argile fine de remonter en surface. Pourquoi existe-t-il une telle différence entre les résultats des deux expérimentations ? La photographie de la coupe du Mont Houy [ill. 1] montre clairement l'existence de couches de quelques centimètres d'épaisseur de couleurs différentes. Les prélèvements sont peut-être issus de niveaux aux consistances contrastées.

Les vases issus du plus ancien four du Technopôle (120-190 de notre ère) présentent de gros nodules d'argilites, visibles dans la pâte et en surface [ill. 3], qui ont amené à une fissuration des vases et donc à leur mise au rebut [ill. 4]. Cette production, considérée comme impropre à la commercialisation, est absente des contextes de consommation, ce qui suggère qu'il s'agissait d'un premier test.

La présence d'argile sableuse à Famars a amené au développement d'une batterie de cuisine capable de résister aux chocs thermiques. Le répertoire culinaire cuit en mode $B$, contrairement aux productions élaborées en mode $A$ apportées des ateliers de Bavay, est inspiré d'ateliers voisins comme ceux du Cambrésis. Faute de savoir traiter les argiles à quartz, les potiers habitués aux pâtes calcaires ont été contraints d'améliorer et transformer leurs malaxages, au gré de tests plus au moins réussis. L'évolution chronologique des mélanges mis en évidence appuie l'hypothèse d'une recherche constante d'un meilleur résultat (Willems, Borgers, 2016).

Références bibliographiques

BeAusSART P., 1976, « L'exploration archéologique de Famars : Les données du Haut-Empire », Revue du Nord, LVIII, n² 231, p. 621-671.

Clotuche R., 2013, Fanum Martis : une agglomération à vocation religieuse et commerciale à la frontière du territoire nervien, Pagus Fano Martensis un terroir spécifique?, rapport de projet collectif de recherche, Villeneuve-d'Ascq, $339 \mathrm{p}$.

Clotuche R. (coord.), Clerget J., Teysseire G. TIXAdOR A., 2017, Fouille du Technopôle Transalley à Famars, rapport d'opération SRA Picardie/Inrap.

Herbin P., Roger D., Calonne E., 2005 « Une production de céramique commune à pâte claire à Famars (Nord) », in PolfER M. (éd.), Artisanat et économie romaine: Italie et provinces occidentales de l'Empire, Actes du $3^{\text {e }}$ colloque international d'Erpeldange (Luxembourg) sur l'artisanat romain, Montagnac, M. Mergoil, p. $147-168$.

Tuffreau-Libre M., VANbrugghe N., 1994, " La céramique du III $^{\mathrm{e}}$ siècle du site de Famars (Nord) », in Tuffreau-Libre M., JACQues A. (éd.), La céramique du Bas-Empire en Gaule Belgique et dans les régions voisines, actes de la table ronde, Revue du Nord H.S. n 4, Arras, p. 33-41.

VAllin L., Prévost-Boure P., 1990, « Le gisement paléolithique du Mont Houy à Trith-Saint-Léger (Nord). Étude de deux niveaux archéologiques dans leur contexte géomorphologique », Bulletin de la Société préhistorique française, vol. 87/2, p. 57-64.

Willems S., Borgers B., 2016, « Pottery workshops at Fanum Martis (Northern France). Analysis of pottery production and consumption ", Acta Rei Cretariae Romanae Fautorum, 44, p. 429-437. 